\title{
Synthesis of 1,4-Dihydropyridines Bearing a Carbamate Moiety on the 4-Position
}

\author{
Davood Habibi, Mohammad Ali Zolfigol, and Maliheh Safaee \\ Department of Organic Chemistry, Faculty of Chemistry, Bu-Ali Sina University, Hamedan 6517838683, Iran \\ Correspondence should be addressed to Davood Habibi; davood.habibi@gmail.com
}

Received 20 May 2013; Accepted 8 July 2013

Academic Editor: Augusto C. Tome

Copyright (C) 2013 Davood Habibi et al. This is an open access article distributed under the Creative Commons Attribution License, which permits unrestricted use, distribution, and reproduction in any medium, provided the original work is properly cited.

A good range of 1,4-dihydropyridines bearing a carbamate moiety on the 4-position were synthesized from the primary reaction of different hydroxyaldehydes with phenyl isocyanates and the subsequent reaction of the obtained carbamates with methyl acetoacetate in the presence of ammonium fluoride. When phenyl isothiocyanate was used in place of phenyl isocyanate in the same condition, the reaction did not take place.

\section{Introduction}

1,4-Dihydropyridines and their derivatives have gained considerable importance in the field of organic and medicinal chemistry since they have fascinating pharmacological properties [1-9]. The 1,4-dihydropyridine skeleton is common in many to be useful as calcium channel blockers $[10,11]$, and they are used most frequently as drugs such as nifedipine, nicardipine, and amlodipine which have been found as cardiovascular agents for the treatment of hypertension [12]. Moreover, studies have discovered that 1,4-dihydropyridines exhibit diverse medical functions such as neuroprotectants, platelet antiaggregators, and chemosensitizers and are important in Alzheimer's disease as anti ischaemic agents [13, 14]. However, preparation of new type of 1,4-dihydropyridines is an active ongoing research area, and there is scope for further improvement toward milder reaction conditions and improved yields. We demonstrated that the ammonium salt could be replaced with ammonia [15]. A number of improved methods have been reported in the literature for this condensation which involve the use of microwave, ionic liquids, reflux high temperature, $\mathrm{AlCl}_{3} \cdot 6 \mathrm{H}_{2} \mathrm{O}$ [16], ultrasound irradiation [17], tetrabutylammonium hydrogen sulfate [18], cyanuric chloride [19], molecular iodine [20], silica gelsupported sodium bisulfate [21], TMSCl-NaI [22], scandium(III) triflate [23], CAN [24], iron(III) trifluoroacetate and trifluoromethanesulfonate [25], organocatalysed [26], silica gel/sulfonic acid [27], PTSSA [28], montmorillonite K10 clay [29], and phenylboronic acid [30]. Additionally, dihydropyridines are often produced in a synthetic sequence and have to be oxidized to pyridines [31].

The most interesting aspect of dihydropyridines can be attributed to the coenzyme reduced nicotinamide adenine dinucleotide (NADH) and the unique ability of these compounds in biological systems to reduce unsaturated functionalities and also strained ring systems (carbonyls, conjugated olefins, epoxides, etc.) [32]. Although 1,4-dihydropyridines with various aromatic, heteroaromatic [33], aliphatic, and sugar [34] substituents at C4 have been reported, there is no report of 1,4-dihydropyridines bearing carbamate substituent at $\mathrm{C} 4$.

\section{Result and Discussion}

We decided to develop the chemistry of this class of compounds and also provide a clean and easy work-up procedure. In continuation of our researches on the synthesis of heterocycles [35-41], we herein report a good range of 1,4dihydropyridines which have a carbamate moiety on the 4position. They were synthesized from a primary reaction of different hydroxyaldehydes with phenyl isocyanates and the subsequent reaction of the obtained carbamates with methyl acetoacetate in the presence of ammonium fluoride 


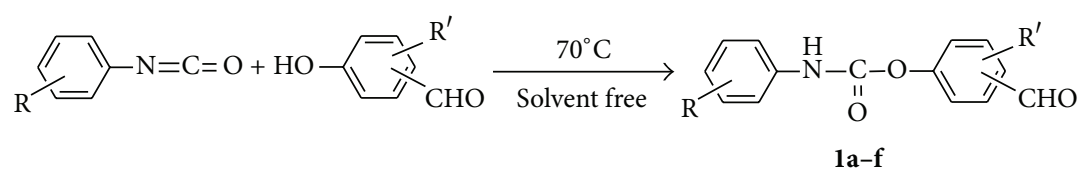

Scheme 1: Preparation of different carbamates from phenyl isocyanates and aldehydes.

TABLE 1: Synthesis of various carbamate derivatives (1a-f).

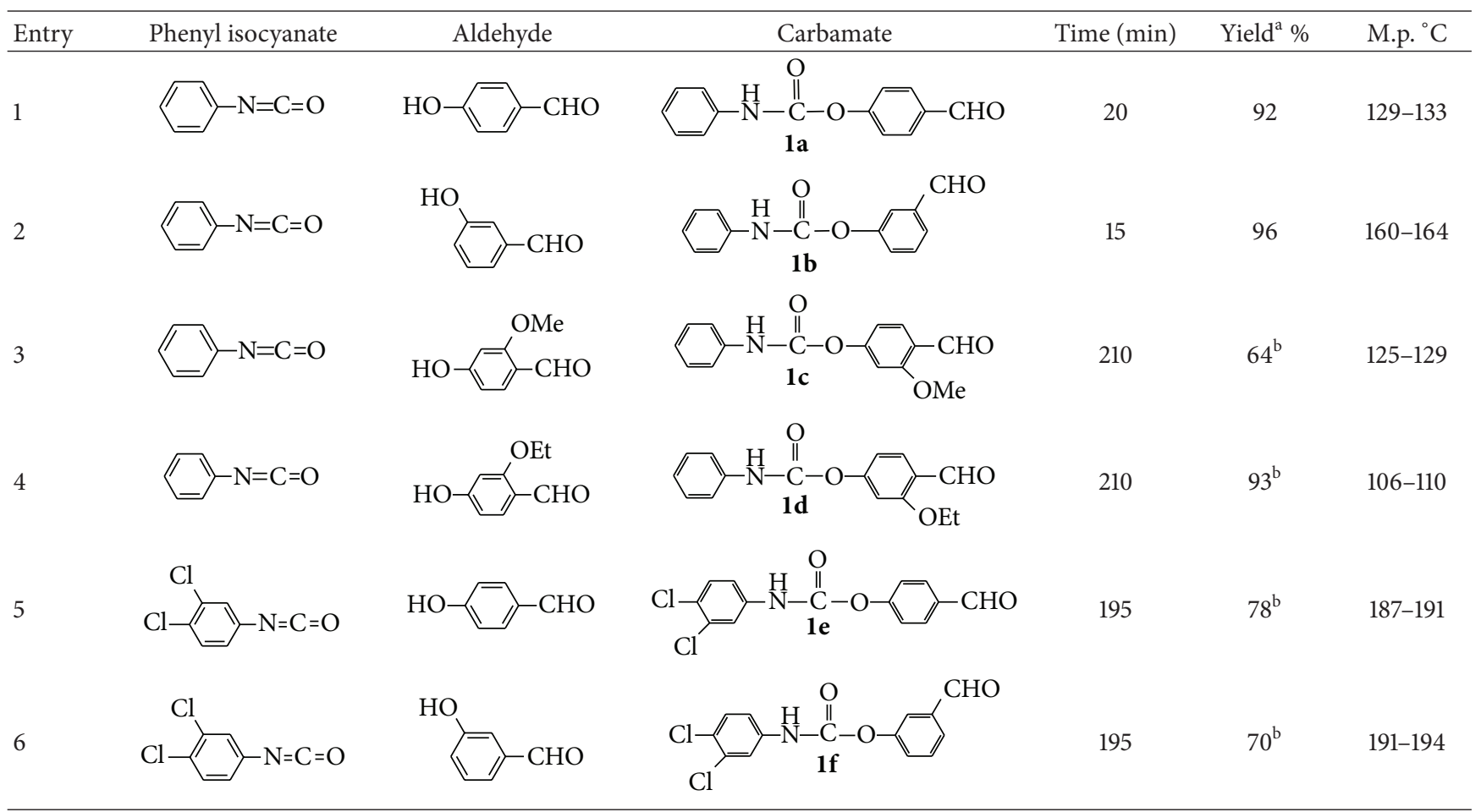

${ }^{\mathrm{a}}$ Isolated yield.

${ }^{\mathrm{b}}$ Reaction took place in ethyl acetate.

(Scheme 1 and Table 1). The obtained carbamates $\left(\mathrm{R}^{\prime \prime} \mathrm{CHO}\right.$, la-f) will then react with methyl acetoacetate in the presence of ammonium fluoride to give different 1,4-dihydropyridines (2a-f, Scheme 2 and Table 2).

When phenyl isothiocyanate was used instead of phenyl isocyanate in the same condition, the reaction did not take place. Also, when ammonium carbonate was used instead of ammonium fluoride, the dihydropyridine which contains phenolic group at 4-position and phenylcarbamic acid were obtained. So dimethyl 2,6-dimethyl-4-(4-(phenylcarbamoyloxy)phenyl)-1,4-dihydropyridine-3,5-dicarboxylate (2a) will be hydrolyzed to dimethyl 4-(4-hydroxy-phenyl)-2,6-dimethyl-1,4-dihydro-pyridine-3,5-dicarboxylate (3a, m.p. 224$226^{\circ} \mathrm{C}$ ) and phenylcarbamic acid in the presence of ammonium carbonate (Scheme 3). Apparently, the released water from ammonium carbonate hydrolyzes the carbamate part of the dihydropyridines.

All compounds were characterized by ${ }^{1} \mathrm{H}$ NMR and IR. In the ${ }^{1} \mathrm{H}$ NMR spectrum of the 1,4-dihydropyridines a peak at 4.3-4.92 ppm belongs to the proton at C-4 position. In the IR spectrum, a strong absorbance peak for the N$\mathrm{H}$ group of the corresponding 1,4-dihydropyridines appears at $3277-3336 \mathrm{~cm}^{-1}$ (Figure 1, see Supporting Information available online at http://dx.doi.org/10.1155/2013/495982).

\section{Experimental}

All reagents were purchased from the Merck and Aldrich chemical companies and used without further purification. Products were characterized by spectroscopy data (FT-IR, ${ }^{1} \mathrm{H}$ NMR spectra). The NMR spectra were recorded in $\mathrm{CDCl}_{3}$, acetone, and DMSO. ${ }^{1} \mathrm{H}$ NMR spectra were recorded on a Bruker Avance DRX $90 \mathrm{MHz}$ instrument. The chemical shifts $(\delta)$ are reported in ppm relative to the TMS as internal standard. FT-IR $(\mathrm{KBr})$ spectra were recorded on a PerkinElmer 781 spectrophotometer. Melting points were taken in open capillary tubes with a BUCHI 510 melting point apparatus and were uncorrected. The elemental analysis was performed using Heraeus CHN-O-Rapid analyzer. TLC was performed on silica gel polygram SIL G/UV 254 plates.

3.1. General Procedure for the Synthesis of Carbamates (1af). A mixture of hydroxybenzaldehydes $(1.0 \mathrm{mM})$ and phenyl isocyanate derivatives $(1.0 \mathrm{mM})$ was stirred in ethyl acetate or 


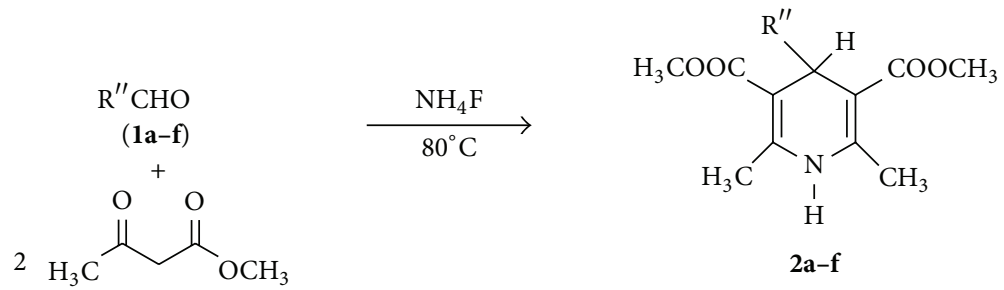

Scheme 2: Preparation of different 1,4-dihydropyridines from carbamates and methyl acetoacetate.

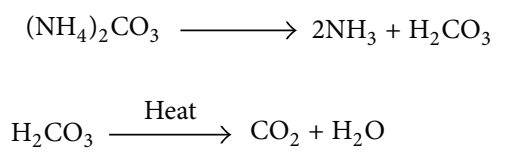<smiles>CC(=O)OC(=O)C1=C(C)NC(C)=C(C(C)=O)C1c1ccc(OC(=O)Nc2ccccc2)cc1</smiles><smiles>CCOCCOc1ccc(C2C(C(=O)OC)=C(C)NC(C)=C2C(=O)OCCO)cc1</smiles>

SCHEME 3: Hydrolysis of 2a.

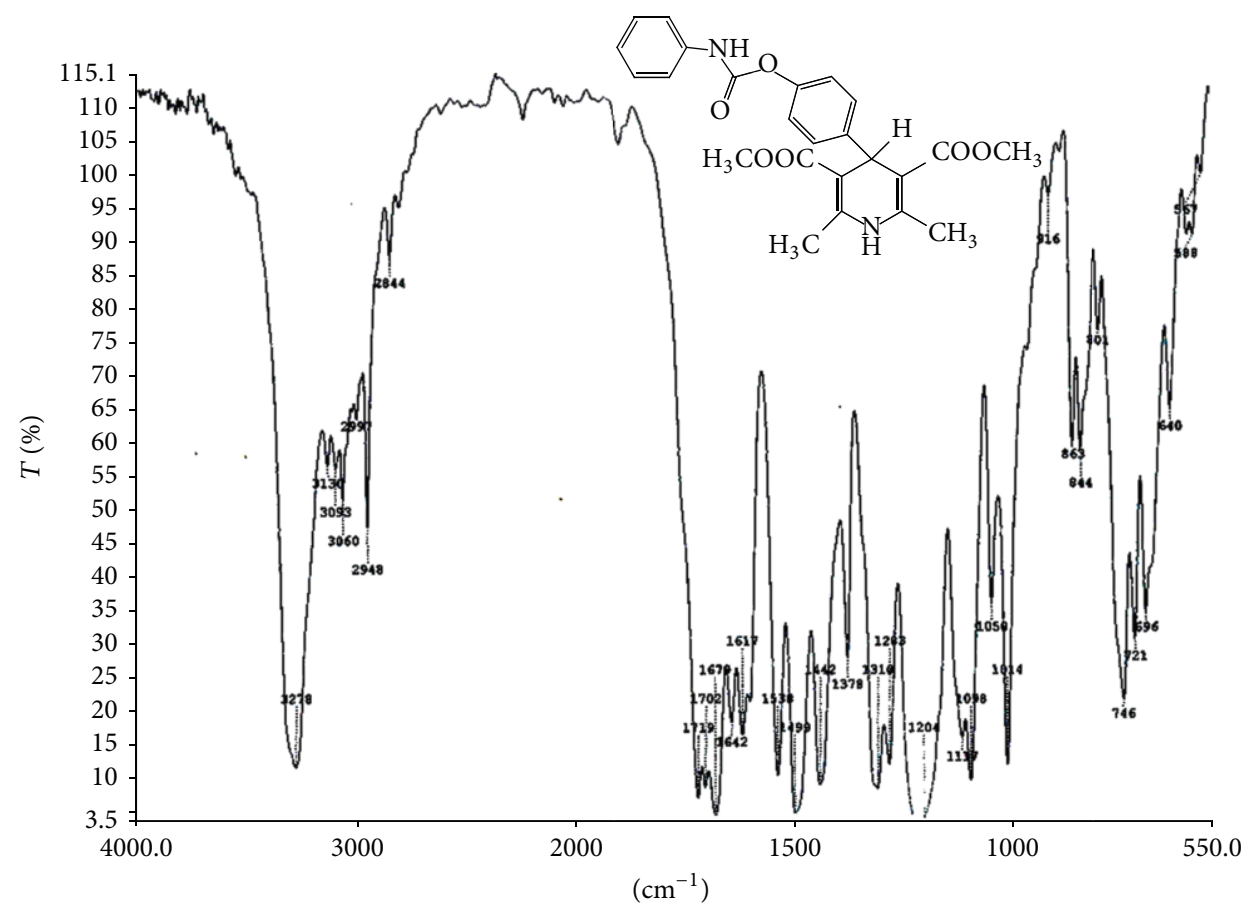

FIGURE 1: IR spectrum of dimethyl 2,6-dimethyl-4-(4-(phenylcarbamoyloxy)phenyl)-1,4-dihydropyridine-3,5-dicarboxylate (2a). 
TABLE 2: Synthesis of 1,4-dihydropyridine derivatives (2a-f).

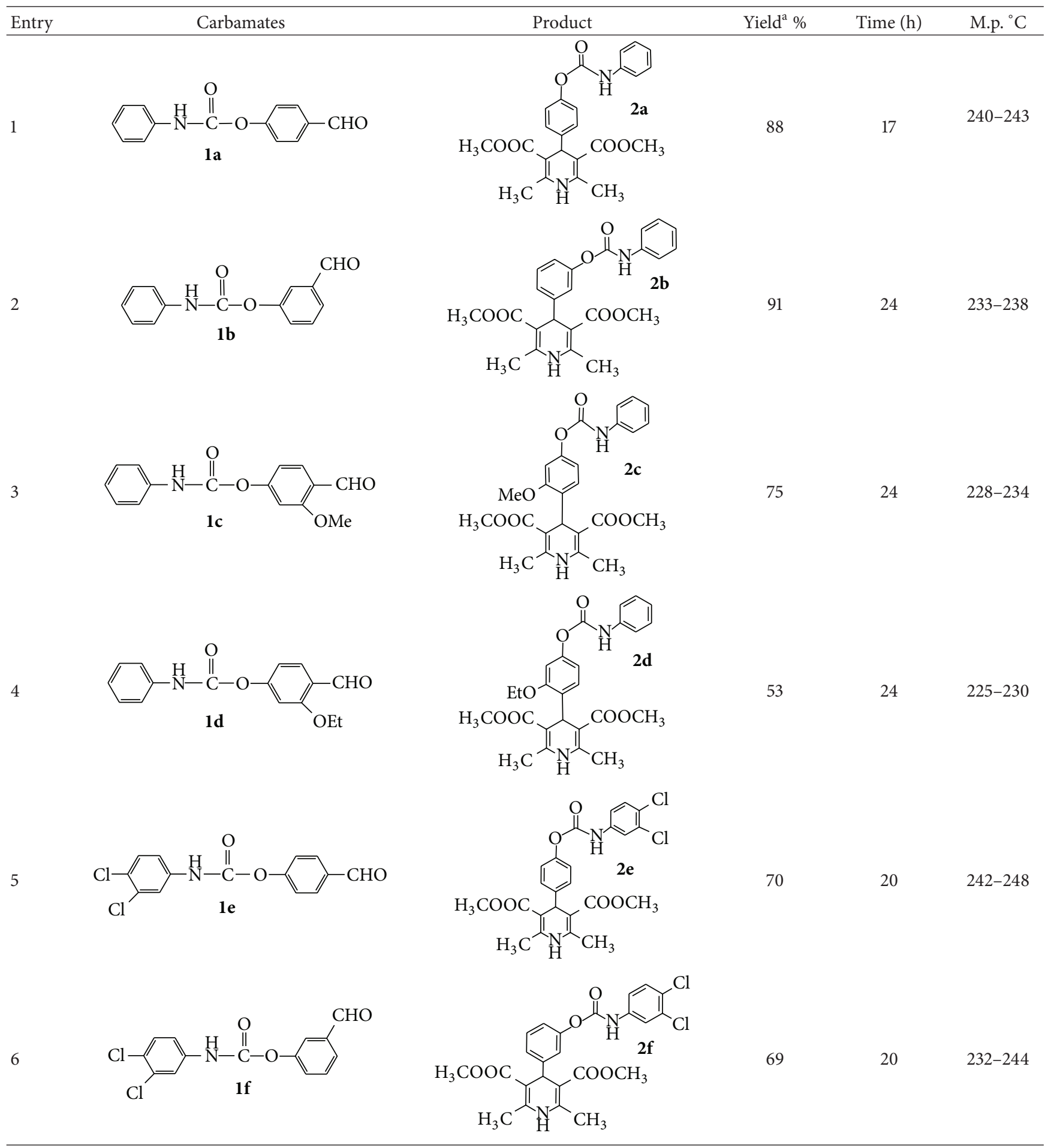

${ }^{\mathrm{a}}$ Isolated yield.

solvent-free at $70^{\circ} \mathrm{C}$ in an appropriate time, and progress of the reaction was monitored by TLC (Scheme 1, Table 1). After completion, the suspension was cooled, ethyl acetate evaporated, the solid was crystallized in ethanol to get the pure carbamates, and the obtained crystals were characterized by ${ }^{1} \mathrm{H}$ NMR and IR.
3.2. Typical Procedure for the Synthesis of 1,4-Dihydropyridines (2a-f). A mixture of carbamate $(1.0 \mathrm{mM})$, methyl acetoacetate $(2.0 \mathrm{mM})$, and ammonium fluoride $(2.0 \mathrm{mM})$ was stirred in ethyl acetate at $80^{\circ} \mathrm{C}$ for appropriate time, and progress of the reaction was monitored by TLC (Scheme 2, Table 2). After completion, the suspension was cooled, ethyl 
acetate evaporated, and ethanol was added to dissolve any impurities since the 1,4-dihydropyridines donot dissolve in ethanol. The obtained solid was pure and characterized by ${ }^{1} \mathrm{H}$ NMR and IR.

\section{Conclusions}

We demonstrated the synthesis of a good range of 1,4dihydropyridines which have a carbamate moiety on the 4position from the primary reaction of different aldehydes with phenyl isocyanate and the subsequent reaction of the obtained carbamates with methyl acetoacetate in the presence of ammonium fluoride. As stated before, when phenyl isothiocyanate was used instead of phenyl isocyanate in the same condition, the reactions did not take place.

\section{Disclosure}

The authors of the paper do not have a direct financial relation with the commercial identities mentioned in this paper.

\section{Acknowledgment}

The authors gratefully acknowledge the financial support from the Bu-Ali Sina University, Hamedan, Iran.

\section{References}

[1] A. R. Trivedi, D. K. Dodiya, B. H. Dholariya, V. B. Kataria, V. R. Bhuva, and V. H. Shah, "Synthesis and biological evaluation of some novel $\mathrm{N}$-aryl-1,4- dihydropyridines as potential antitubercular agents," Bioorganic and Medicinal Chemistry Letters, vol. 21, no. 18, pp. 5181-5183, 2011.

[2] V. P. Pandey, S. S. Bisht, M. Mishra et al., "Synthesis and molecular docking studies of 1-phenyl-4-glycosyl-dihydropyridines as potent antileishmanial agents," European Journal of Medicinal Chemistry, vol. 45, no. 6, pp. 2381-2388, 2010.

[3] K. Sirisha, D. Bikshapathi, G. Achaiah, and V. M. Reddy, "Synthesis, antibacterial and antimycobacterial activities of some new 4-aryl/heteroaryl-2,6-dimethyl-3,5-bis- $N$-(aryl)-carbamoyl-1,4-dihydropyridines," European Journal of Medicinal Chemistry, vol. 46, no. 5, pp. 1564-1571, 2011.

[4] K. Sirisha, M. C. Shekhar, K. Umasankar et al., "Molecular docking studies and in vitro screening of new dihydropyridine derivatives as human MRP1 inhibitors," Bioorganic and Medicinal Chemistry, vol. 19, no. 10, pp. 3249-3254, 2011.

[5] M. Kawase, A. Shah, H. Gaveriya et al., "3,5-Dibenzoyl-1,4dihydropyridines: synthesis and MDR reversal in tumor cells," Bioorganic and Medicinal Chemistry, vol. 10, no. 4, pp. 1051-1055, 2002.

[6] M. Suárez, Y. Verdecia, B. Illescas et al., "Synthesis and study of novel fulleropyrrolidines bearing biologically active 1,4dihydropyridines," Tetrahedron, vol. 59, no. 46, pp. 9179-9186, 2003.

[7] R. Shan, C. Velazquez, and E. E. Knaus, "Syntheses, calcium channel agonist-antagonist modulation activities, and nitric oxide release studies of nitrooxyalkyl 1,4-dihydro2,6-dimethyl-3-nitro-4-(2,1,3-benzoxadiazol-4-yl) pyridine-5carboxylate racemates, enantiomers, and diastereomers," Journal of Medicinal Chemistry, vol. 47, no. 1, pp. 254-261, 2004.
[8] N. I. Ryabokon, R. I. Goncharova, G. Duburs, and J. Rzeszowska-Wolny, "A 1,4-dihydropyridine derivative reduces DNA damage and stimulates DNA repair in human cells in vitro," Mutation Research, vol. 587, no. 1-2, pp. 52-58, 2005.

[9] T. Yamamoto, S. Niwa, S. Ohno et al., "Structure-activity relationship study of 1,4-dihydropyridine derivatives blocking $N$-type calcium channels," Bioorganic and Medicinal Chemistry Letters, vol. 16, no. 4, pp. 798-802, 2006.

[10] R. A. Janis and D. J. Triggle, "New developments in calcium ion channel antagonists," Journal of Medicinal Chemistry, vol. 26, pp. 775-785, 1983.

[11] R. H. Böcker and F. P. Guengerich, "Oxidation of 4-aryland 4-alkyl-substituted 2,6-dimethyl-3,5-bis(alkoxycarbonyl)1,4-dihydropyridines by human liver microsomes and immunochemical evidence for the involvement of a form of cytochrome P-450," Journal of Medicinal Chemistry, vol. 29, no. 9, pp. 1596$1603,1986$.

[12] F. R. Buhler and W. Kiowski, "Calcium antagonists in hypertension," Journal of Hypertension, vol. 5, no. 3, pp. s3-s10, 1987.

[13] V. Klusa, "Cerebrocrast. Neuroprotectant, cognition enhancer," Drugs of the Future, vol. 20, no. 2, pp. 135-138, 1995.

[14] R. G. Bretzel, C. C. Bollen, E. Maeser, and K. F. Federlin, "Nephroprotective effects of nitrendipine in hypertensive type I and type II diabetic patients," American Journal of Kidney Diseases, vol. 21, no. 6, pp. 53-64, 1993.

[15] M. A. Zolfigol and M. Safaiee, "Synthesis of 1,4-dihydropyridines under solvent-free conditions," Synlett, no. 5, pp. 827-828, 2004.

[16] S. Das Sharma, P. Hazarika, and D. Konwar, "A simple, green and one-pot four-component synthesis of 1,4-dihydropyridines and their aromatization," Catalysis Communications, vol. 9, no. 5, pp. 709-714, 2008.

[17] S.-X. Wang, Z.-Y. Li, J.-C. Zhang, and J.-T. Li, “The solvent-free synthesis of 1,4-dihydropyridines under ultrasound irradiation without catalyst," Ultrasonics Sonochemistry, vol. 15, no. 5, pp. 677-680, 2008.

[18] N. Tewari, N. Dwivedi, and R. P. Tripathi, "Tetrabutylammonium hydrogen sulfate catalyzed eco-friendly and efficient synthesis of glycosyl 1,4-dihydropyridines," Tetrahedron Letters, vol. 45, no. 49, pp. 9011-9014, 2004.

[19] G. V. M. Sharma, K. L. Reddy, P. S. Lakshmi, and P. R. Krishna, “"In situ" generated "HCl"- an efficient catalyst for solventfree Hantzsch reaction at room temperature: synthesis of new dihydropyridine glycoconjugates," Synthesis, no. 1, Article ID P05205SS, pp. 55-58, 2006.

[20] S. Ko, M. N. V. Sastry, C. Lin, and C.-F. Yao, "Molecular iodinecatalyzed one-pot synthesis of 4-substituted-1,4- dihydropyridine derivatives via Hantzsch reaction," Tetrahedron Letters, vol. 46, no. 34, pp. 5771-5774, 2005.

[21] M. Adharvana Chari and K. Syamasundar, "Silica gel/NaHSo catalyzed one-pot synthesis of Hantzsch 1,4-dihydropyridines at ambient temperature," Catalysis Communications, vol. 6, no. 9, pp. 624-626, 2005.

[22] G. Sabitha, G. S. K. K. Reddy, C. S. Reddy, and J. S. Yadav, "A novel TMSI-mediated synthesis of Hantzsch 1,4dihydropyridines at ambient temperature," Tetrahedron Letters, vol. 44, no. 21, pp. 4129-4131, 2003.

[23] S. Kikuchi, M. Iwai, H. Murayama, and S.-I. Fukuzawa, "Catalytic synthesis of 1,4-dihydropyridine derivatives using scandium(III) triflate," Tetrahedron Letters, vol. 49, no. 1, pp. 114-116, 2008. 
[24] V. Sridharan, P. T. Perumal, C. Avendaño, and J. C. Menéndez, "A new three-component domino synthesis of 1,4-dihydropyridines," Tetrahedron, vol. 63, no. 21, pp. 4407-4413, 2007.

[25] H. Adibi, H. A. Samimi, and M. Beygzadeh, "Iron(III) trifluoroacetate and trifluoromethanesulfonate: recyclable Lewis acid catalysts for one-pot synthesis of 3,4-dihydropyrimidinones or their sulfur analogues and 1,4-dihydropyridines via solventfree Biginelli and Hantzsch condensation protocols," Catalysis Communications, vol. 8, no. 12, pp. 2119-2124, 2007.

[26] A. Kumar and R. A. Maurya, "Organocatalysed three-component domino synthesis of 1,4-dihydropyridines under solvent free conditions," Tetrahedron, vol. 64, no. 16, pp. 3477-3482, 2008.

[27] R. Gupta, R. Gupta, S. Paul, and A. Loupy, "Covalently anchored sulfonic acid on silica gel as an efficient and reusable heterogeneous catalyst for the one-pot synthesis of Hantzsch 1,4dihydropyridines under solvent-free conditions," Synthesis, no. 18, pp. 2835-2838, 2007.

[28] A. Kumar and R. A. Maurya, "Efficient synthesis of Hantzsch esters and polyhydroquinoline derivatives in aqueous micelles," Synlett, no. 6, pp. 883-885, 2008.

[29] A. M. Zonouz and S. B. Hosseini, "Montmorillonite K10 clay: an efficient catalyst for Hantzsch synthesis of 1,4-dihydropyridine derivatives," Synthetic Communications, vol. 38, no. 2, pp. 290296, 2008.

[30] A. Debache, R. Boulcina, A. Belfaitah, S. Rhouati, and B. Carboni, "One-pot synthesis of 1,4-dihydropyridines via a phenylboronic acid catalyzed Hantzsch three-component reaction," Synlett, no. 4, pp. 509-512, 2008.

[31] M. M. Heravi, F. K. Behbahani, H. A. Oskooie, and R. H. Shoar, "Catalytic aromatization of Hantzsch 1,4-dihydropyridines by ferric perchlorate in acetic acid," Tetrahedron Letters, vol. 46, no. 16, pp. 2775-2777, 2005.

[32] H. R. Memarian and A. Mirjafari, "Solid state photochemistry of 1,4-dihydropyridines," Bioorganic and Medicinal Chemistry Letters, vol. 15, no. 14, pp. 3423-3425, 2005.

[33] A. Zarghi, H. Sadeghi, A. Fassihi, M. Faizi, and A. Shafiee, "Synthesis and calcium antagonist activity of 1,4-dihydropyridines containing phenylaminoimidazolyl substituents," Farmaco, vol. 58, no. 11, pp. 1077-1081, 2003.

[34] A. Dondoni, A. Massi, and E. Minghini, "Two- and three-component Hantzsch reaction using C-glycosylated reagents. Approach to the asymmetric synthesis of 1,4diyhydropyridines," Synlett, no. 1, pp. 89-92, 2002.

[35] M. Nasrollahzadeh, Y. Bayat, D. Habibi, and S. Moshaee, " $\mathrm{FeCl}_{3}$ $\mathrm{SiO}_{2}$ as a reusable heterogeneous catalyst for the synthesis of 5-substituted $1 \mathrm{H}$-tetrazoles via [2+3] cycloaddition of nitriles and sodium azide," Tetrahedron Letters, vol. 50, no. 31, pp. 44354438, 2009.

[36] D. Habibi, M. Nasrollahzadeh, A. R. Faraji, and Y. Bayat, "Efficient synthesis of arylaminotetrazoles in water," Tetrahedron, vol. 66, no. 21, pp. 3866-3870, 2010.

[37] M. Nasrollahzadeh, D. Habibi, Z. Shahkarami, and Y. Bayat, "A general synthetic method for the formation of arylaminotetrazoles using natural natrolite zeolite as a new and reusable heterogeneous catalyst," Tetrahedron, vol. 65, no. 51, pp. 1071510719, 2009.

[38] D. Habibi and M. Nasrollahzadeh, "Silica-supported ferric chloride $\left(\mathrm{FeCl}_{3}-\mathrm{SiO}_{2}\right)$ : an efficient and recyclable heterogeneous catalyst for the preparation of arylaminotetrazoles," Synthetic Communications, vol. 40, no. 21, pp. 3159-3167, 2010.
[39] D. Habibi and M. Nasrollahzadeh, "Synthesis of arylaminotetrazoles by $\mathrm{ZnCl}_{2} / \mathrm{AlCl}_{3} /$ silica as an efficient heterogeneous catalyst," Monatshefte fur Chemie, vol. 143, no. 6, pp. 925-930, 2012.

[40] D. Habibi, M. Nasrollahzadeh, and T. A. Kamali, "Green synthesis of the 1-substituted $1 H$-1,2,3,4-tetrazoles by application of the Natrolite zeolite as a new and reusable heterogeneous catalyst," Green Chemistry, vol. 13, no. 12, pp. 3499-3504, 2011.

[41] D. Habibi and M. Nasrollahzadeh, " $\mathrm{ZnO}$ as an effective and reusable heterogeneous catalyst for the synthesis ofarylaminotetrazoles," Synthetic Communications, vol. 42, pp. 20232032, 2012. 

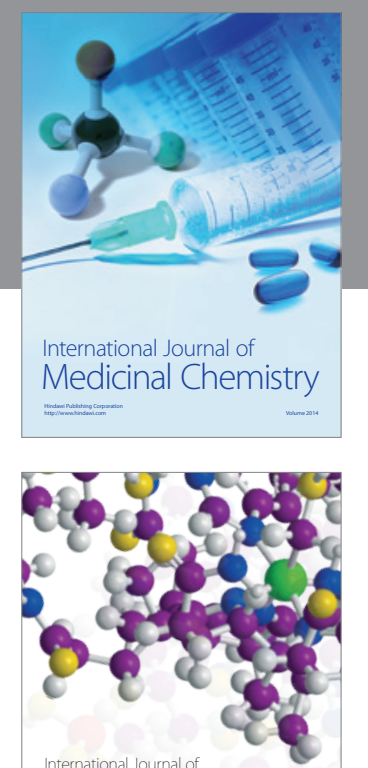

\section{Carbohydrate} Chemistry

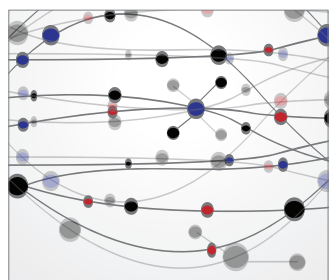

The Scientific World Journal

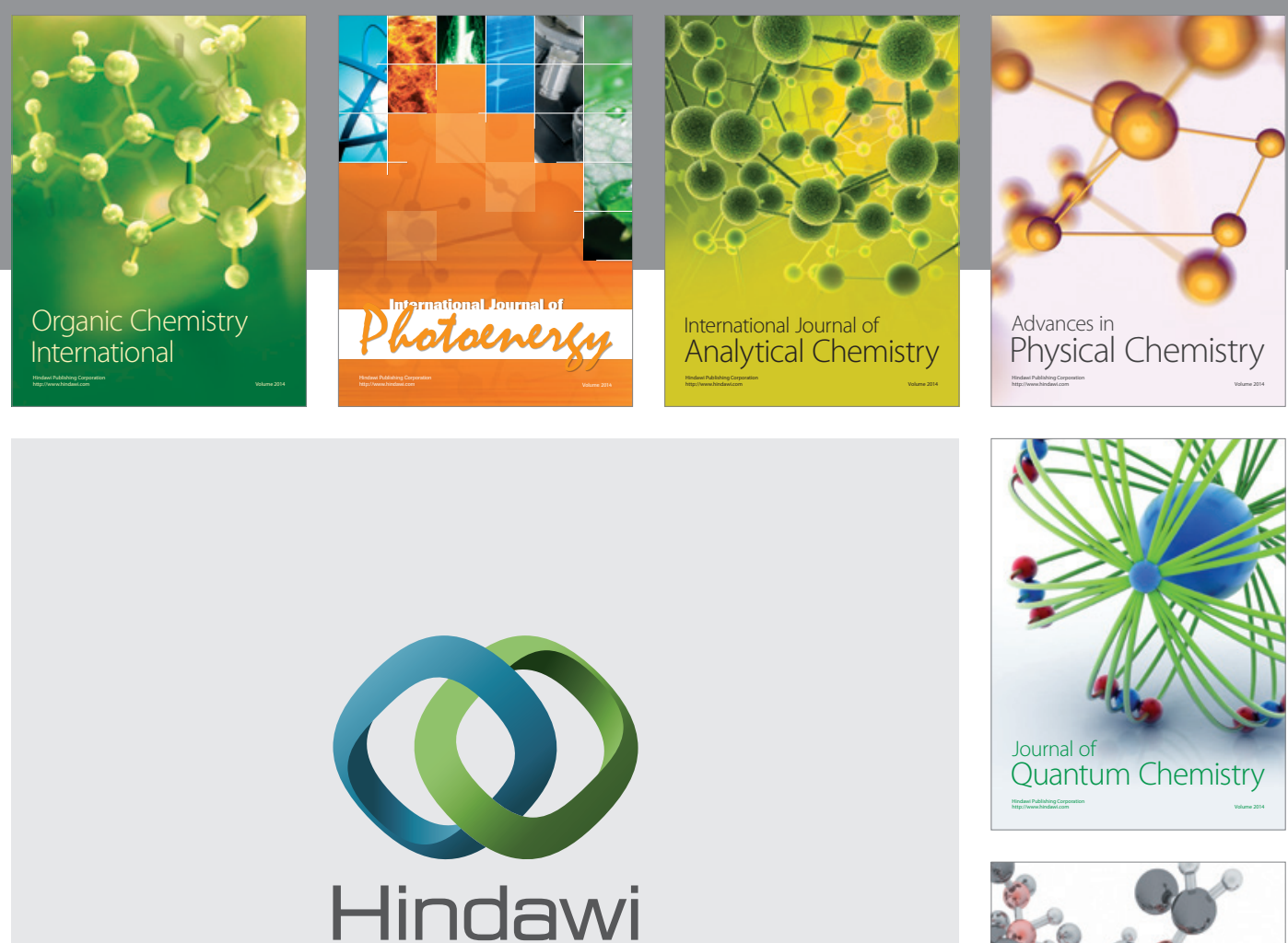

Submit your manuscripts at

http://www.hindawi.com

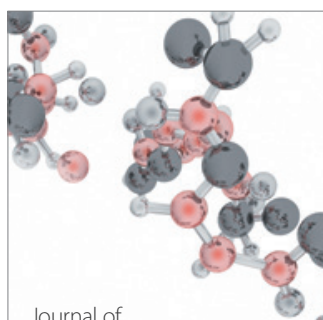

Analytical Methods

in Chemistry

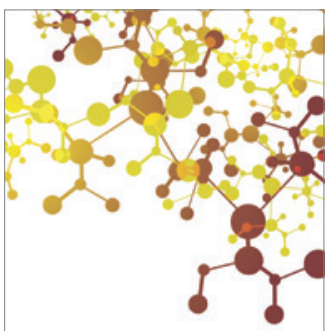

Journal of

Applied Chemistry

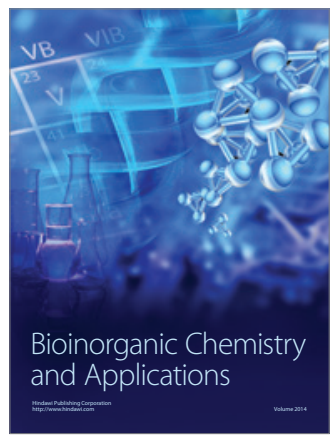

Inorganic Chemistry
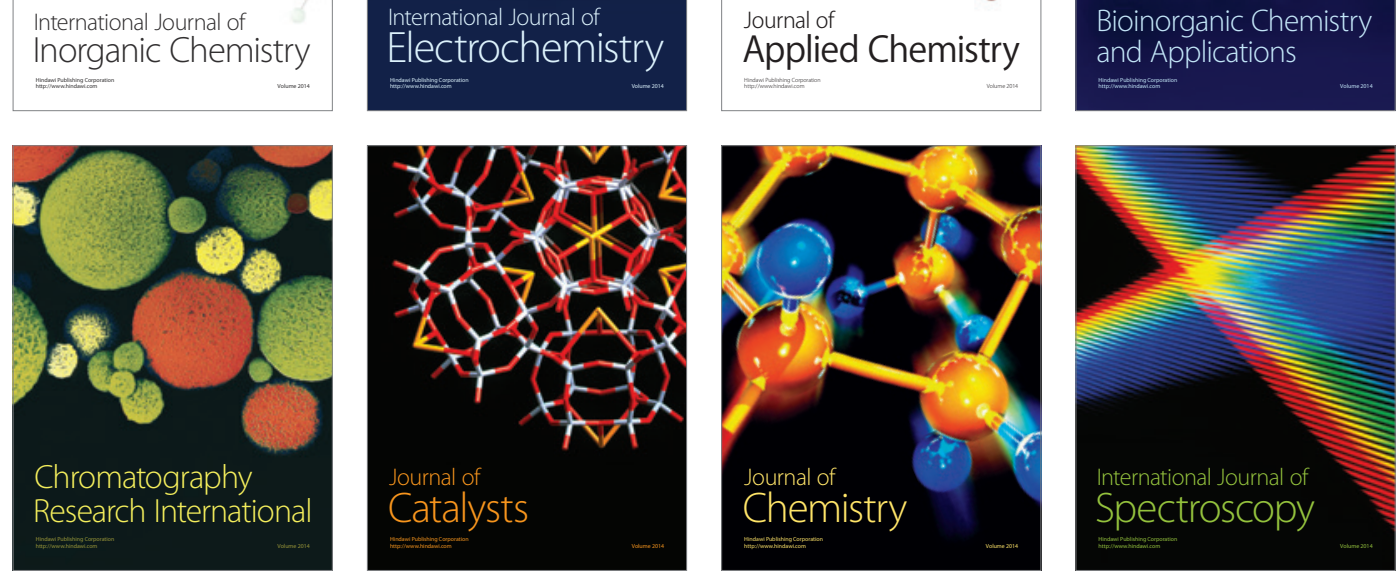